\title{
O MARCO INSTITUCIONAL DA POLÍTICA URBANA NA ESPANHA E APONTAMENTOS COMPARATIVOS COM 0 BRASIL 1
}

\author{
Jefferson Oliveira Goulart \\ é professor do Departamento de Ciências Humanas da Universidade Estadual Paulista (Unesp). \\ E-mail:<jgoulart@faac.unesp.br> \\ http://dx.doi.org/10.1590/0102-233259/103
}

\section{A configuração constitucional}

A constituição espanhola de 1978 sintetiza os fundamentos do modelo territorial, da organização do Estado e das competências dos níveis de governo quanto à política urbana (Título VIII). São quatro os níveis de organização territorial: o próprio Estado (governo central), os municípios, as províncias e as comunidades autônomas, e todos "gozam de autonomia para a gestão de seus respectivos interesses" (artigo 137). Municípios e províncias têm "personalidade jurídica própria" $(\text { artigos } 140 \text { e 141) })^{2}$. No caso das comunidades autônomas, se

1 Este artigo apresenta resultados de pesquisa pós-doutoral desenvolvida no Departamento de Sociología II (Ecología Humana y Población) da Universidad Complutense de Madrid, Espanha. Agradecimentos do autor à Fundação de Amparo à Pesquisa do Estado de São Paulo pela concessão de Bolsa de Pesquisa no Exterior (Processo Fapesp 2015/11625/7) e a Luis Cortés Alcalá, pela acolhida generosa. Versão modificada deste trabalho foi apresentada no XVII Encontro da Associação Nacional de Pós-Graduação e Pesquisa em Planejamento Urbano e Regional.

2 As províncias se limitam ao agrupamento supramunicipal e à divisão territorial, não têm competências administrativas ou recursos para implantação de políticas públicas ou para manutenção de infraestrutura urbana. Portanto, 
reconhece o "autogoverno" (artigo 143), solução encontrada para responder às renitentes reivindicações nacionalistas e independentistas de algumas identidades regionais, casos mais agudos do País Vasco (Euskadi) e da Cataluña - além da Galícia, a terceira "comunidade histórica".

A Espanha não é rigorosamente um Estado unitário, na medida em que tem quatro níveis de organização político-territorial com algum grau de autonomia, e tampouco é uma federação com um correspondente sistema de freios e contrapesos que efetivamente assegure alto coeficiente autonômico aos governos subnacionais. Ademais, não há referência constitucional detalhada às competências dos entes governamentais em matéria de política urbana.

Não obstante as atribuições conferidas às esferas locais e autonômicas de governo, em termos de distribuição orçamentária a estrutura estatal se mantém relativamente 234 centralizada: "los gobiernos locales de las ciudades padecen un déficit crónico de recursos en la distribución del gasto público" (Blanco; Subirats, 2012, p. 25), dispondo de aproximadamente $14 \%$ de todo o gasto público do país. O levantamento de Salgado (2011) demonstra que a porcentagem do gasto público era distribuída da seguinte maneira: Estado - 83\%; governos regionais - 7\%; governos locais $-10 \%$. Houve uma reconcentração de recursos em relação ao ano de 1983, pois os governos regionais e locais regrediram do patamar de $17 \%$ para $14 \%$ do gasto público no período atual.

Embora o arranjo institucional mencione a "exclusividade" das comunidades autônomas em urbanismo e regulação territorial, há um sistema compartilhado em que os governos autonômicos dispõem de recursos privilegiados,

não serão consideradas como nível de governo com atribuições na gestão de políticas urbanas. 
no entanto, os municípios também têm responsabilidades na execução de políticas públicas dessa natureza.

A Espanha conta com dezessete comunidades autônomas, que constituem as principais esferas governativas além do Estado ${ }^{3}$. Se aos municípios e às províncias dedica-se pouca tinta, a constituição é mais generosa com as comunidades autônomas, cujas competências mais importantes estão dispostas no artigo 148: responsabilidade pela "ordenação do território, urbanismo e habitação”. Na prática, cabe às comunidades autônomas legislar e organizar o processo de ordenamento territorial e desenvolvimento urbano, tanto no plano municipal quanto em escala regional ${ }^{4}$. Nesse contexto, políticas urbanas não se resumem às ações dos governos locais, e o marco institucional espanhol se distingue por expressivo poder das comunidades autônomas. Também por essa razão, os temas da descentralização e da autonomia são recorrentes, e ganham força a cada impulso autonomista ou separatista.

A constituição é genérica quanto à política urbana e se limita a enunciar princípios gerais, sem instituir correspondentes instrumentos para torná-los efetivos. Os dois princípios fundamentais são a regulação do solo urbano para conter a especulação imobiliária e o reconhecimento de que a ocorrência de mais-valia urbana implica correspondente contrapartida dos entes privados (orientados pela lógica da acumulação) ao Estado (orientado pelo interesse público).

3 São elas: Galícia, Principado de Astúrias, Cantabria, País Vasco (Euskadi), Navarra, Aragón, Cataluña, Castilla y León, La Rioja, Comunidad de Madrid, Extremadura, Castilla-La Mancha, Comunidad Valenciana, Islas Baleares, Andalucía, Murcia e Islas Canarias. Ademais, as cidades de Ceuta e Melilla (enclaves situados no Marrocos) gozam de estatuto autonômico especial.

4 As comunidades autônomas ainda têm competências quanto a: alterações territoriais dos municípios; obras públicas; organização dos sistemas de transporte rodoviário e ferroviário; disposição de equipamentos como portos e aeroportos; gestão de políticas de meio ambiente; gestão de projetos de recursos hidráulicos; saúde e saneamento. (<http://www.senado.es/web/conocersenado/normas/constitucion/index.html>, acesso em: 14 out. 2017). 
Tais conflitos terão vazão político-jurídica na legislação infraconstitucional e nas competências dos governos autonômicos. $\mathrm{O}$ arranjo institucional da política urbana ganha mais nitidez no âmbito infraconstitucional, particularmente nas competências e políticas públicas operadas pelas comunidades autônomas e nas normas de regulação do território urbano com base na Ley de Suelo e nos Planes de Ordenación Urbana.

\section{Evolução urbana e a Ley de Suelo}

$\mathrm{O}$ desenvolvimento urbano da Espanha no século XX teve elementos distintivos: pela forma politicamente autoritária e regionalmente discricionária com que o regime franquista conduziu o país; pela tentativa de acelerar a modernização da economia por meio do processo de industrialização a partir da década de 1950; pelas clivagens regionais que diferenciaram áreas economicamente mais dinâmicas (industriais, turísticas etc.) de outras mais atrasadas

236 (rurais e vinculadas à agropecuária), com distintos graus de urbanização; e pelas mudanças na distribuição espacial da população resultantes de migrações do campo rumo às grandes aglomerações urbanas.

De forma sintética, a evolução urbana na Espanha a partir da segunda metade do último século enseja um percurso marcado por quatro etapas (Costa et al., 2013). O primeiro momento, situado nas décadas de 1960 e 1970, registra forte migração interna rumo às cidades decorrente do impulso ao padrão de desenvolvimento urbano-industrial, movimento desigual em termos espaciais pela concentração de complexos industriais em territórios restritos (Cataluña e Euskadi, sobretudo).

A segunda fase tem como marco a democratização, a partir de 1979, e se estende a meados da década seguinte, registrando a emergência de diversos movimentos citadinos (Castells, 1980) que desafiaram o regime autoritário e lidaram com uma complexa agenda de problemas urbanos (infraestrutura, 
habitação, mobilidade etc.), além de registrar a adesão do país à Comunidade Econômica Europeia, em 1986.

Na terceira etapa, basicamente ao longo dos anos 1990, de crise do padrão fordista, de mudança de modelos produtivos e de ascensão do capital financeiro, são registrados os movimentos de metropolização e terceirização da economia, elevando-se a importância do terceiro setor, chamado a integrar a governança urbana.

A quarta fase tem início no final dos anos 1990 e segue até o período contemporâneo, coincidindo com a adesão plena do país à União Europeia. Os destaques dessa etapa são a precedência do eixo econômico na agenda urbana, a migração de origem externa para o mercado de trabalho de baixa qualificação, a intensificação do espraiamento horizontal das cidades, a relativa estabilização demográfica dos grandes centros urbanos e a acentuação da especulação imobiliária.

A urbanização espanhola tem se caracterizado por um modelo de desenvolvimento impulsionado por uma forte bolha imobiliária que, além de incrementar a construção civil, contou com o suporte de uma legislação permissiva. Algumas das principais consequências desse processo foram (i) a ocupação indiscriminada e ampliação do território urbano, sob a pressão do mercado imobiliário e do argumento da necessidade crescente de prover serviços e bens públicos (infraestrutura, moradia etc.), e (ii) o aumento abusivo do preço da terra urbana e da habitação (Parellada, 2009).

A principal norma de ordenamento do território urbano é a Ley de Suelo, cuja primeira versão é de 1956. Esse marco legal instituiu três categorias de solo - "urbano", "urbanizável” e "não urbanizável” -, cuja caracterização compete ao poder público. No direito urbanístico espanhol considera-se "solo urbanizável todo aquele solo que não foi classificado pelo Plan General de Ordenamiento como urbano (tecido urbano consolidado) ou como não urbanizável (solos protegidos)" (Alfonsin, 2008, p. 67, grifos do autor). 
A Ley de Suelo reconheceu as plusvalias urbanas e instituiu o princípio da participação da comunidade nos benefícios gerados pela ação do poder público, ou seja, ao mesmo tempo que reconhece o solo como mercadoria também impõe algum grau de compensação do ganho privado, instituindo o princípio genérico de que a propriedade privada e os empreendedores imobiliários devem restituir ao erário parte de seus ganhos obtidos com os investimentos estatais.

A primeira reforma do texto da lei se deu em 1976, motivada pelo cenário de transição para a democracia, pelos processos de adensamento nas grandes cidades e em suas zonas centrais, pela desordem urbanística com crescente ocupação periférica das cidades e pela elevação especulativa do preço do solo urbano. A classificação tipológica do solo se manteve inalterada: urbano, urbanizável e não urbanizável.

Em 1992, nova mudança, considerada uma "lei de passa238 gem” pela expectativa de adaptação às grandes transformações em curso - ideológicas (onda neoliberal), geopolíticas (fim da Guerra Fria) e econômico-urbanísticas (crise do padrão industrial e emergência do setor terciário) - e pelo pouco tempo de vigência (seis anos depois haveria nova mudança) ou, ainda, pela contestação de inconstitucionalidade apresentada por sete comunidades autônomas, cujos itens mais controversos eram o aproveitamento lucrativo das áreas de superfície e a definição institucional sobre as competências de gestão da política urbana. $\mathrm{O}$ aspecto institucional mais relevante dessa reforma foi o reconhecimento da autonomia conferida às comunidades autônomas na agenda do planejamento urbano. A sentença 61/97 do Tribunal Constitucional deliberou pela competência "exclusiva" das comunidades autônomas em matéria de política urbana.

Em 1998, nova modificação, cuja vigência coincide com o ciclo mais intenso de urbanização e modernização econômica do país e com o ambiente hegemônico de desregulamentação 
no continente europeu: legislação de abertura irrestrita ao processo urbanizador, cuja concepção liberalizante se amparava na escassez de solo urbanizado edificável e de oferta de moradia, bem como na elevação crescente dos preços do solo. Assim é criada a figura jurídica do "Agente Urbanizador", ente privado para o qual o poder público poderia transferir a responsabilidade de promover urbanização (Parellada, 2009).

O estudo da implantação do "Agente Urbanizador" no caso valenciano evidencia que "trata-se de um instrumento jurídico-urbanístico que separa o direito de propriedade imobiliária do direito de urbanizar a gleba, permitindo que a urbanização possa ser proposta por um empreendedor não proprietário" (Alfonsin, 2008, p. 63). Apesar de se tratar de responsabilidade estatal e de função pública, a urbanização é transferida para terceiros, o que obviamente chancela uma concepção mercadológica desse processo à medida que qualquer empreendedor só o assumirá se isso for economicamente recompensador.

A reforma de 1998 é o emblema da tendência liberalizante daquele período e transcorreu no governo conservador de José María Aznar, do Partido Popular (PP). O argumento consistia em dispor de um tipo de regulação que não limitasse a ação do capital, separando as atribuições do proprietário e as do urbanizador, e o solo da construção. Em consequência, sob amparo legal a expansão urbana atinge o limite do solo rústico protegido. A tipologia adotada - "Suelo urbano consolidado e no consolidado"; "Solo urbanizable: delimitado y no delimitado"; "Solo no urbanizable" - admite a urbanização de áreas protegidas com base em caracterização e critérios excepcionais convenientes aos empreendedores imobiliários. Na prática, todo território passou a ser considerado "em princípio urbanizável”, o que contraria o próprio enunciado da regulação urbanística quanto à autoridade restritiva do Estado sobre a ação do mercado imobiliário. A definição residual do solo urbanizável constitui o tema-síntese de uma reforma que pretendeu 
se adaptar às mudanças econômicas decorrentes da crise do modelo fordista de produção para uma expansão urbanística inspirada pelos princípios neoliberais (Rullan, 1999).

Em 2007, mais uma reforma na tentativa de atualizar a legislação. Nessa ocasião ficaram evidentes os conflitos entre as pressões para o crescimento econômico e uma visão de desenvolvimento sustentável retoricamente estimulada na União Europeia. A contradição é expressa no reconhecimento do solo como "recurso natural, escasso e não renovável", mas também como "recurso econômico". Essa reforma ratificou a concepção desenvolvimentista e subordinou o planejamento urbano ao crescimento econômico, o que se traduziu em maior permissividade à transformação do solo não urbanizável em seu oposto (urbanizável). Tal perspectiva ganhou nova nomenclatura, distinguindo-se basicamente dois tipos de solo: urbanizado, definido como todo aquele no qual já se construiu ou com determinado grau de 240 aporte urbanístico, e o rural, entendido como solo natural, protegido, de reserva e também como bem econômico.

A modificação mais recente ocorreu em 2015 (Real Decreto Legislativo $n^{\circ} 7 / 2015$ ), em texto refundido que promoveu uma justaposição conceitual e adequação jurídica da lei $n^{\circ}$ 20/2014, do decreto legislativo $n^{\circ}$ 2/2008 e da lei no 8/2013, que trata da reabilitação, regeneração e renovação urbanísticas. A nomenclatura herdada de 2007 se manteve, havendo basicamente dois regimes de solo: urbanizado e rural (artigo 21 da referida lei).

Apesar das várias modificações legais (Quadro 1), houve um acelerado processo inflacionário no mercado imobiliário, uma vez que "a regra básica do jogo (a valorização artificial do solo urbano segundo seu potencial urbanístico) não foi alterada" (Alfonsin, 2008, p. 70). Vale a pena lembrar o emblemático caso valenciano: "o valor do solo passa de $6 €$ para $300 € \mathrm{o} \mathrm{m}^{2}$ com a aprovação da normativa urbanística que lhe transforma em 'solo urbanizável', ainda que o proprietário 
não tenha realizado nenhum investimento" (Alfonsin, 2008, p. 70). Tais normas agravam a crise urbana, pois alimentam a especulação imobiliária, elevam o valor da terra urbanizada e concorrem para pressionar o poder público a ampliar o escopo de "terras urbanizáveis" através das Leis do Solo autonômicas e dos Planes de Ordenación Urbana.

\section{Quadro 1}

Evolução cronológica da Ley de Suelo

\begin{tabular}{|c|c|}
\hline ANO & MARCO LEGAL \\
\hline 1956 & $\begin{array}{l}\text { Legislação original: Ley sobre Régimen del Suelo y Ordenación Urbana LS/56 } \\
\text { Classes de solo: Suelo urbano; Suelo de reserva urbana; Suelo rústico } \\
\text { Cenário político: VI governo da ditadura de Francisco Franco }\end{array}$ \\
\hline 1976 & $\begin{array}{c}\text { Real Decreto 1346/1976, que aprova o Texto Refundido de la Ley sobre } \\
\text { Régimen del Suelo y Ordenación Urbana (TRLS/76) } \\
\text { Classes de solo: Suelo Urbano; Suelo Urbanizable; Suelo no urbanizable } \\
\text { Cenário político: governo de Adolfo Suárez (Unión de Centro Democrático } \\
\text { - UCD) }\end{array}$ \\
\hline 1992 & $\begin{array}{c}\text { Real Decreto Legislativo 1/1992, que aprova o Texto Refundido de la Ley } \\
\text { sobre el Régimen del Suelo y Ordenación Urbana (TRLS/92) } \\
\text { Classes de solo: Suelo Urbano; Suelo Urbanizable; Suelo no urbanizable } \\
\text { Cenário político: governo de Felipe González (Partido Socialista Obrero } \\
\text { Español - PSOE) }\end{array}$ \\
\hline 1998 & $\begin{array}{l}\text { Ley de Suelo 6/1998, de Régimen del suelo y valoraciones (LS/98) } \\
\text { Classes de solo: Suelo urbano consolidado e no consolidado; } \\
\text { Solo urbanizável; delimitado e não delimitado; Solo não urbanizável } \\
\text { Cenário político: governo de José María Aznar (Partido Popular - PP) }\end{array}$ \\
\hline $2007 / 2008$ & $\begin{array}{c}\text { Ley de Suelo 8/2007 (LS 8/07) e posterior regulamentação com o Real } \\
\text { Decreto Legislativo 2/2008, que aprova o Texto Refundido de la Ley de Suelo } \\
\text { (TRLS/08) } \\
\text { Classes de solo: Suelo urbanizado (suelo usado); } \\
\text { Suelo rural (suelo para usar + suelo protegido) } \\
\text { Cenário político: governo de José Luiz Zapatero (Partido Socialista Obrero } \\
\text { Español - PSOE) }\end{array}$ \\
\hline 2015 & $\begin{array}{l}\text { Real Decreto Legislativo 7/2015, pelo qual se aprova o texto refundido de La } \\
\text { Ley de Suelo y Rehabilitación Urbana: resultado da fusão da Ley 20/2014, do } \\
\text { Real Decreto Legislativo 2/2008 e da Ley 8/2013 (reabilitação, regeneração e } \\
\text { renovação urbanas) } \\
\text { Classes de solo: suelo urbanizado e suelo rural (artigo 20) } \\
\text { Cenário político: governo de Mariano Rajoy (Partido Popular - PP) }\end{array}$ \\
\hline
\end{tabular}

Fonte: elaboração própria. 
Esse processo de urbanização no derradeiro quartel do século XX é inseparável da observação de Rullan (1999), segundo a qual a internacionalização da economia espanhola fez com que houvesse um deslocamento do capital nacional, do setor produtivo para o imobiliário: o ingresso de investimentos transnacionais em segmentos industriais e de serviços ensejou uma transferência de controle sobre essas atividades e estimulou o capital nacional a migrar rumo ao setor imobiliário. Isso fez com que o capital disponível não só não ficasse imobilizado, mas também impossibilitado de obter maior lucratividade em iniciativas rentáveis, tais como incorporações, urbanização, empreendimentos imobiliários e até estocagem de glebas à espera de futuras valorizações decorrentes da expansão urbana e das fortes pressões sobre o poder público para ampliar continuamente o escopo das terras urbanizáveis.

O problema estrutural (ampliação das terras urbanizá242 veis) encontra amparo no direito urbanístico espanhol, ou seja, "por atividade urbanística se entende a toda atividade pública destinada a promover a adequada transformação de um solo rural em solo urbano" (Araujo Jr., 2013, p. 893-894).

Essa proposição guarda estreita sintonia com a interpretação de Harvey (2013): a raiz da crise estaria precisamente na sua própria incapacidade de absorver excedentes de capital, ou seja, crises de sobreacumulação gerariam desvalorização e destruição de algumas regiões e construção de outras, ensejando um fenômeno de "acumulação por espoliação" que, por definição, concentra capital e priva a maioria da sociedade de seus direitos. Ou seja, o deslocamento de parte do capital rumo às atividades imobiliárias foi determinado por essa sobreacumulação e pela participação do capital financeiro, o que contribuiu decisivamente para a bolha imobiliária que se revelou altamente rentável para seus empreendedores. Esse movimento foi possível pela permissividade da legislação urbanística, 
particularmente da Ley de Suelo e suas sucessivas reformas, o que condicionou as legislações autonômicas e pautou a formatação dos planos urbanísticos.

\section{Os Planes de Ordenación Urbana}

Se a Constituição enuncia os preceitos gerais da ordenação urbana (função social da propriedade, plusvalias urbanas e competências governamentais), se a Ley de Suelo institui a tipologia de solos (urbano e rural) e organiza as regras de regulação urbanística, e se as leis autonômicas do solo se adaptam à legislação estatal em seus territórios, a adequação e a aplicação dessas normas competem ao Plan General de Ordenación Urbana (PGOU), aqui tratado como Plan de Ordenación Urbana (Quadro 2).

A primeira versão da Ley de Suelo, de 1956, já previa que o planejamento era a base necessária e fundamental de toda ordenação urbana - e que o Plan de Ordenación Urbana constituía um instrumento privilegiado para tanto -, predizendo a elaboração e execução de planos territoriais de várias escalas: nacional, provinciais, comarcais e municipais. Tais planos podem ter abrangência espacial variada, interessando neste estudo, inclusive para efeitos comparativos com o cenário institucional brasileiro, aqueles de escala local.

Planes de Ordenación Urbana são atribuições dos governos autonômicos. Essa modelagem institucional impõe duplicidade jurisdicional na medida em que, embora sejam propostos pelos governos locais (ayuntamientos) - que também têm atribuições aplicativas complementares -, os Planes devem ser submetidos à apreciação e aprovação das administrações autonômicas. Planos urbanísticos são avaliados técnica e politicamente no âmbito das comunidades autônomas

\footnotetext{
5 A nomenclatura a respeito do mesmo instrumento é variada, refletindo a diversidade cultural e linguística do país. Em Andalucía, Castilla y León e Valencia, é Plan General de Ordenación Urbanistica (PGOU); na Cataluña, Pla d'Ordenació Urbana Municipal (POUM); na Galicia, Plan Xeral de Ordenación Municipal (PXOM).
} 
pelos órgãos tecnocráticos de planejamento e pelos correspondentes foros institucionais de diferentes denominações: Asamblea (Madri), Generalitat (Valencia), Xunta (Galícia), Junta (Andalucía) e assim sucessivamente.

\section{Quadro 2}

Sequência hierárquica de aplicação da legislação urbanística na Espanha

\begin{tabular}{c}
$\begin{array}{c}\text { Constituição [abrangência nacional - foro decisório: Congreso de los Diputados } \\
\text { e Senado] } \\
\downarrow\end{array}$ \\
\hline Ley de Suelo Estatal [incidência nacional - foro decisório: Congreso de los \\
Diputados] \\
$\downarrow$
\end{tabular}

Fonte: elaboração própria.

Consideradas a legislação urbanística e as decisões arbitradas pelo Tribunal Constitucional quanto ao conflito de competências dos diferentes níveis de governo, sobretudo as sentenças 61/97 e 164/01 após a controversa reforma da Ley de Suelo de 1990, ao Estado (governo central) cabe estabelecer diretrizes gerais da política urbana, enquanto as comunidades autônomas têm competências "exclusivas" (legislativas) em matéria de urbanismo. Tais prerrogativas, na verdade, são compartilhadas (na dimensão aplicativa) com os municípios (ayuntamientos) à medida que estes detêm funções regulatórias consagradas pela Ley de Bases de Régimen Local (lei nº 7/1985), dentre as quais merecem registro a autoridade em "planejamento, gestão, execução e 
disciplina urbanística; proteção e gestão do patrimônio histórico; promoção e gestão da habitação de proteção pública com critérios de sustentabilidade financeira" (artigo 25, 2a).

Está correta a perspectiva que interpreta a política urbana espanhola como um caso "multinível", no sentido de um arranjo institucional complementar em que diferentes esferas e níveis de governo têm competências complementares nesse âmbito (Blanco; Subirats, 2012). No sistema espanhol outras regulações setoriais também têm bases decisórias no domínio do Estado ou das comunidades autônomas. É o caso das normas sobre uso, ocupação e controle das regiões de costas marítimas, recursos hídricos e autoridade hidráulica, logística (sistemas de rodovias, ferrovias e transporte aéreo de carga e passageiros), organização territorial supramunicipal etc. Portanto, Planes de Ordenación Urbana devem levar em conta, respeitar e não afrontar tais regulações, do contrário podem ser contestados juridicamente (Medrano, 2015).

Ganhar expressão jurídica não representa necessariamente granjear efetividade, pois políticas públicas exprimem a face real do Estado e podem alterar ou manter o status quo (Souza, 2007). Toda regulação deriva de alguma forma de arbitragem de conflitos sociopolíticos e implica o estabelecimento de normas, as quais traduzem determinado consenso dotado de legitimidade. Isso significa que a sobreposição de diferentes órgãos e níveis de governo em um mesmo tema torna mais complexa a implantação de qualquer política pública, pois compreende múltiplas dimensões negociais que envolvem as diferentes autoridades correspondentes e os públicos atingidos.

Ainda que planos urbanísticos possam ter baixa eficácia e não se realizarem plenamente, cumprem um papel determinante como ideologia, ou seja, como instrumento de dominação e imposição de determinada concepção de mundo e de organização urbana que se legitima como aspiração de toda a sociedade (Villaça, 2004). Portanto, a 
potência do urbanismo transcendeu sua capacidade efetivamente transformadora do espaço urbano precisamente porque sua força ideológica residia na projeção idealizada da cidade. Assim, a lógica dos modernistas "acabaria desembocando na concepção mecanicista do urbanismo e da habitação, a casa como machine à habiter, no aforismo que logo popularizaria Le Corbusier” (De La Rosa, 2014, p. 154).

A partir da democratização política e da promulgação dos estatutos de autonomia nas décadas de 1980-1990, proliferaram legislações autonômicas de ordenação do território e Planes de Ordenación Urbana. A generalização dessa prática, contudo, não pode ser associada à efetividade em razão da prevalência de uma concepção generalista que postulava diretrizes e, por isso mesmo, era refém de grandes dificuldades operacionais impostas aos planos urbanísticos (De Córdoba, 2007).

A influência modernista, a concepção generalista e a baixa capacidade reguladora contribuíram decisivamente 246 para forjar a sensação de impotência do urbanismo e a percepção de ineficácia dos planos urbanísticos, os quais coincidem com a crise do modelo fordista de produção capitalista, com a difusão do ideário neoliberal e com a emergência de um novo paradigma: o "planejamento estratégico das cidades". Nesses termos, "sem uma estratégia de políticas urbanas própria, sem processos de implicação social, os governos locais veem submetidas suas dinâmicas a agentes externos que ditam projetos e ritmos" (Blanco; Subirats, 2012, p. 24).

O colapso do modelo fordista expôs o confronto entre duas concepções de ordenação econômica (Clarke, 1991). A primeira, orientada pela tradição keynesiana, é marcada pela perspectiva de dotar as instituições nacionais de maior capacidade para enfrentar situações de crise, com base em um novo equilíbrio entre produção e demanda por meio de um forte papel regulador exercido pelo Estado na expectativa de promover um cenário de pleno emprego - concepção que se confundiu com as experiências do welfare state. 
A segunda orientação, nomeada como monetarista, advogava a impossibilidade de manutenção do Estado do bem-estar e a adoção de um modelo liberal que encontraria seu equilíbrio na espontaneidade das forças do mercado, cuja estabilidade seria alcançada por meio de políticas e instrumentos monetários, mediante a supressão do papel regulador do Estado. Não por acaso, essa doutrina econômica encontrou sua expressão ideológica no pensamento neoliberal.

Essas mudanças na ordem econômica também se refletiram nas concepções urbanísticas e na gestão das cidades a partir da crise das cidades industriais, emergindo crescentes demandas por governos locais empreendedores. Assim, ocorre uma alteração importante na atribuição desses governos, que deixariam de ser responsáveis pela provisão de infraestrutura, bens e serviços urbanos (gerenciadores) para se tornarem empreendedores econômicos incumbidos de proporcionar a modernização de negócios em seus respectivos territórios; enfim, o empresariamento das cidades (Harvey, 1996). Para radicalizar o argumento, as cidades seriam reduzidas à dimensão mercadológica, e governos locais deveriam assumir atribuições antes conferidas aos níveis superiores (Castells; Borja, 1996). Supondo que as cidades competem entre si para atrair investimentos, nada mais coerente que tratá-las como autênticas mercadorias, em conformidade com a hegemonia neoliberal. O empresariamento das cidades é a expressão de uma forma sofisticada de "reificação (coisificação) da cidade" (Harvey, 1996, p. 53), e no caso espanhol essa tendência coincidiu com o boom imobiliário da última década do século XX e primeiro decênio do XXI.

O amparo legal para essas mudanças na concepção do planejamento urbano foi encontrado no ordenamento institucional, nos planos urbanísticos e na implantação de projetos arquitetônicos e urbanísticos de grande impacto. Coerente com essa visão mercadológica da cidade, emergiu a tentativa de conferir atualidade e eficácia aos planos, isto é, 
a crítica implícita à impotência e à ineficácia do urbanismo convencional abriu espaço para se disseminar a concepção do planejamento estratégico das cidades. Nesta acepção, o contexto institucional e a realidade sociopolítica são substituídos por modelos dirigidos à competição e à mercantilização da cidade em suas múltiplas dimensões.

A narrativa neoliberal se tornou amplamente hegemônica também na literatura especializada sobre planejamento urbano (Blanco; Subirats, 2012; Griggs; Blanco; Sullivan, 2010; Rullan, 1999) e, embora essas concepções tivessem calorosa recepção e mesmo outras formulações na Espanha, sua matriz teórica está nos Estados Unidos e no paradigma da cidade como legítima máquina de crescimento, ou growth machine (Arantes, 2000; Logan; Molotch, 1987).

Isso não significa que os planos urbanísticos foram inteiramente malsucedidos, mas que seus postulados originais (de ordenação e regulação do solo) foram colocados 248 em xeque porque não se concretizariam integralmente e porque a agenda do desenvolvimento urbano migrou para a temática econômica diante da crise das cidades industriais. Nesse sentido, qualquer avaliação sobre os planos urbanísticos deve considerar suas diferentes dimensões e fases que envolvem sua concepção e execução (De Córdoba, 2007).

Reagir à crise econômica e forjar novos paradigmas de desenvolvimento urbano não significou reagir à desindustrialização, em sentido estrito, com a consequente transposição ou mesmo fechamento de plantas industriais (embora esse fenômeno tenha ocorrido). Na verdade, o que ocorreu em meio às transformações gerais da economia capitalista desse período foi a afirmação da primazia do capital financeiro, uma grande expansão do segmento terciário e dinamização do setor imobiliário. As cidades não deixaram de abrigar indústrias, mas se converteram em lócus privilegiado de sobreposição destas ao pujante setor de serviços, com destaque para o peso crescente do capital imobiliário. 
Há casos emblemáticos de grandes projetos urbanos que mudaram a própria identidade urbanística e econômica de algumas importantes cidades espanholas, como Valencia, Barcelona e Bilbao, nas quais a indústria não "desapareceu", embora tenha se enfraquecido. É provável que o exemplo mais proeminente seja o da siderurgia vasca. A propósito, a expansão do setor de serviços no último período é extraordinária na Espanha, passando de $46 \%$ em 1970 para $75 \%$ do Produto Interno Bruto nacional em 2015. No mesmo período a participação da indústria regride praticamente pela metade, de $34 \%$ para $17,1 \%$ do PIB. A evolução da estrutura do emprego no mesmo ciclo ratifica o enfraquecimento do peso relativo da indústria: os postos de trabalho ocupados nesse setor regridem de 25,3\% para 13,6\%, ao passo que no setor de serviços há enorme crescimento, o qual mais que duplica esse percentual, indo de 36,5\% para 76,2\% (Pampillión, 2016).

A expansão do setor terciário e o aquecimento do mercado imobiliário foram possíveis pela oferta de crédito disponibilizada pelo capital financeiro. Novamente convém recorrer a Harvey (2013) e à sua explicação da crise capitalista contemporânea: estaríamos diante de um movimento de sobreacumulação cuja expressão urbana seria o desmoronamento de alguns espaços econômicos e a edificação de outros ou, ainda, de reconversão daqueles decadentes por meio de crédito do sistema financeiro e de inversões do capital imobiliário altamente rentáveis. A consequência foi um padrão de desenvolvimento territorialmente desigual, em que "a localização do empreendimento é vital para que sua utilidade seja socialmente verificada, pois grandes edifícios sem a proximidade de um mercado consumidor estão sob o risco de ser um fiasco" (Botelho, 2014, p. 87).

As transformações econômicas e urbanísticas e os projetos urbanos de grande impacto que se implantaram nas cidades mencionadas não atropelaram os governos locais e autonômicos - não obstante resistências localizadas, eles próprios foram seus entusiastas e/ou promotores -, pelo contrário, estes foram 
contagiados pela magnitude e pelo impacto de inúmeros projetos urbanos, tanto de requalificação de áreas "degradadas" quanto de outras intervenções urbanísticas "inovadoras" ou de reconversão e gentrification. Como essas iniciativas se relacionaram com os planos urbanísticos? Na verdade, não foram estes que previram e projetaram tais inciativas, mas se adaptaram a elas.

Em Valencia, o Plan General de Ordenación Urbana, de 1991, trata da divisão urbanística e do regime geral do solo e enuncia a subordinação hierárquica às suas regras e diretrizes. Não há contradição entre um plano de caráter geral e outros específicos de qualificação ou requalificação urbana, contudo, salta aos olhos que as intervenções e os grandes projetos urbanos sejam solenemente ignorados (Ayuntamiento..., 2007). Fato é que a flexibilização da categoria de solo "não urbanizável”, a adoção do paradigma Agente Urbanizador que abriu espaço à ação agressiva de grupos imobiliários - e os grandes projetos implantados (como da Ciutat de les Arts $i$ 250 les Ciències $^{6}$ ) tiveram mais influência na produção do espaço urbano do que qualquer plano urbanístico.

O caso de Barcelona parece mais complexo, pela configuração político-institucional da cidade (referência de conflitos territoriais históricos), por sua importância socioeconômica histórica (região de industrialização mais dinâmica do país) ou ainda pela expressiva tradição tecnocrática de planejamento preexistente. Chama atenção, em primeiro lugar, que neste caso a escala vá além do municipal, isto é, há um plano "metropolitano" aprovado em 1976, com sucessivas atualizações ${ }^{7}$. Esse percurso pode ser mais bem compreendido em sua dimensão acentuadamente mercadológica: a ambição de alçar a cidade à

\footnotetext{
6 Projeto assinado pelo arquiteto espanhol Santiago Calatrava, um dos ícones do mainstream da arquitetura contemporânea, associada a estéticas e projetos arrojados e a intervenções urbanísticas de grande impacto. Outro símbolo desta "escola" é o arquiteto canadense Frank Gehry, autor dos projetos do Peix (escultura símbolo da Barcelona pós-olímpica) e do Museu Guggenheim, em Bilbao.

7 Texto legal do Plan General Metropolitano de Barcelona (PGMB) (<http://www.amb. cat/es/web/territori/gestio-i-organitzacio/numamb>, acesso em: 19 maio 2016).
} 
condição de metrópole mundial foi sistematizada pelo "Plano Barcelona 2000", e nesta receita "um pouco de tudo: das gentrificações de praxe às exortações cívicas endereçadas aos chamados atores urbanos, que de recalcitrantes se tornariam cada vez mais cooperativos em torno dos objetivos comuns de city marketing..." (Arantes; Vainer e Maricato, 2000, p. 54). Também nesse caso os megaprojetos subordinaram os planos.

No País Vasco constituiu-se em 1992 a Bilbao Ría 2000, instituição responsável por articular e organizar as ações destinadas à recuperação e reconversão dos antigos espaços industriais e à transição das atividades portuárias para uma transformação urbana declaradamente orientada para os "serviços, a cultura e novas indústrias". Trata-se de uma sociedad anónima de capital público, cujas principais fontes de recursos têm origem na alienação de antigos terrenos industriais e em projetos de requalificação urbana executados em parceria com o capital privado $^{8}$. A política de reconversão urbana teve um estatuto próprio, cuja institucionalização pautou as políticas de desenvolvimento e seu Plan General de Ordenación Urbana, ou seja, o particular (a reconversão econômica) condicionou e ajustou o geral (regras e diretrizes da regulação urbanística). Resultado: o referido Plan General, aprovado em 1994, não só não alude aos projetos do Bilbao Ría 2000 como não adota as premissas e prioridades deste. Na verdade, o segundo se impôs ao primeiro. A síntese urbanística dessa reconversão econômica foi a instalação do Museu Guggenheim.

Em todos esses casos, os Planes de Ordenación Urbana ou não idealizaram as normas urbanísticas e projetos urbanos ou tiveram que absorvê-los uma vez implantados, de modo que a normativa urbanística foi subordinada à agenda da reconversão econômica. Para além de qualquer abstração, eis os exemplos categóricos de autênticas máquinas de crescimento.

8 (<http://www.bilbaoria2000.org/ria2000/cas/home/home.aspx >, acesso em: 19 maio 2016). 
A fragilidade dos planos urbanísticos reflete o marco institucional da política urbana, cuja raiz reside na Ley de Suelo e na tendência de generalizar solo urbano ou urbanizável nos Planes de Ordenación Urbana. Ademais, espelha a primazia da dimensão econômica na agenda do desenvolvimento urbano, que se traduziu na adesão ao empresariamento urbano e na lógica das cidades como máquinas de crescimento, caracterizada, de um lado, por políticas destinadas à promoção urbana e ao desenvolvimento do mercado imobiliário e, de outro, pela articulação de agentes das elites locais (governamentais e privados).

A legislação enuncia que o Plan General de Ordenación Urbana é o instrumento básico para a formulação de políticas urbanas, ao qual compete a classificação do solo, a fixação das bases de um planejamento sustentável, a preservação do solo não urbanizável e a previsão de projetos de renovação ou reabilitação urbana. A realidade revela cenário oposto à normativa, uma vez que os planes de maneira geral não só têm

252 perdido sua centralidade como instrumento de planejamento, mas também são ofuscados ou neutralizados por projetos e ações que contrariam seus postulados. A consequência social desse paradoxo institucional é a intensificação dos contrastes urbanísticos entre a "cidade dos ricos" e a "cidade dos pobres". A "injustiça espacial" que essa polarização enseja emerge como a grande questão urbana contemporânea (Secchi, 2015).

\section{Hipóteses comparativas: Espanha-Brasil}

Sintetizado o quadro institucional da política urbana espanhola, resta esboçar alguns parâmetros comparativos com o cenário brasileiro. Antes, um registro: não há na literatura uma avaliação sistematizada e comparativa sobre os Planes de Ordenación Urbana na Espanha, o que limita um esforço de síntese na medida em que se constatam a existência de estudos particulares de várias disciplinas (urbanismo, direito, economia, sociologia urbana, ciência política), a adoção de diferentes referenciais 
teórico-metodológicos e o exame relativamente insulado de distintas experiências.

Diante dessa lacuna, a hipótese adotada é que o fenômeno crescente de mercantilização urbana - em um contexto de crise e transformação do padrão fordista de produção - foi impulsionado pela hegemonia do ideário neoliberal (Rullan, 1999) e pela estrutura institucional do direito urbanístico (Alfonsin, 2008), ou seja, o objetivo de tornar as cidades economicamente mais competitivas, o caráter flexível das normas urbanísticas e as pressões pela ampliação da oferta de terra urbanizada fizeram com que municípios e comunidades autônomas aderissem à lógica da cidade como máquina de crescimento, e daí para o empresariamento urbano foi um salto rápido e coerente (López; Rodríguez, 2010). Nesse cenário, o poder regulatório dos planos urbanísticos tem sido cada vez menor, uma vez que a ordenação urbana é determinada por outras políticas, normas e projetos, os quais condicionam os Planes de Ordenación Urbana.

Assim, a estrutura institucional se adapta e se submete às forças de mercado, com notável proeminência do segmento imobiliário (Márquez; Naredo, 2011), e à orientação de governos que forjam normas flexíveis para facilitar a consecução desses objetivos. Mas é preciso ressaltar que as bases jurídicas dessas normas constam do próprio arcabouço institucional: a Ley de Suelo prevê basicamente dois tipos de solo (urbanizado ou rural), isto é, a própria legislação induz à irrefreável tendência de expansão do solo urbanizável (artigo 21.2.b).

Em termos normativos, a legislação brasileira é mais incisiva quanto aos instrumentos de direito à cidade (Quadro 3). A Constituição Federal (CF) não só dedica um capítulo específico à política urbana, como em um único enunciado subordina o direito de propriedade à sua função social, reconhece o município como ente federativo responsável pela política urbana e elege o Plano Diretor como instrumento fundamental (artigo 182): “a política de desenvolvimento 
urbano, executada pelo poder público municipal, conforme diretrizes gerais fixadas em lei, tem por objetivo ordenar o pleno desenvolvimento das funções sociais da cidade e garantir o bem-estar de seus habitantes"; depois " $\$ 1^{\circ} \mathrm{O}$ plano diretor, aprovado pela Câmara Municipal, obrigatório para cidades com mais de vinte mil habitantes, é o instrumento básico da política de desenvolvimento e de expansão urbana"; finalmente, " $\$ 2$ A propriedade urbana cumpre sua função social quando atende às exigências fundamentais de ordenação da cidade expressas no plano diretor".

Há uma importante diferença política entre os dois países na história recente de seus processos de democratização. A transição espanhola se distinguiu por um caráter altamente pactuado que se traduziu em soluções de compromisso que conferiram um conteúdo bastante genérico à sua ordenação constitucional. Essa foi a fórmula predominante de concertação em virtude da correlação de forças e da disposição para 254 consensos manifestada por todas as forças e partidos políticos, da direita à esquerda (Maues e Santos, 2008).

No caso brasileiro, a Constituição Federal de 1988 não só é acusada de demasiado detalhismo por sua extensão, como é reconhecidamente avançada em termos de legitimação e expansão de direitos sociais, civis e políticos. Essas distinções se refletiram nas definições da política urbana e na ordenação institucional do princípio participativo, tanto que as normas brasileiras são bem mais generalizadas (em várias áreas de políticas públicas) e específicas (detalhadas). Convém lembrar que o texto constitucional brasileiro tem origem em emenda de iniciativa popular ( $\mathrm{n}^{\mathrm{o}} 63$ ), organizada pelo Movimento Nacional da Reforma Urbana (MNRU), tendo coletado 133.068 assinaturas (Michiles et al., 1989).

Nesses termos, não surpreende que o regramento e a institucionalização também tenham sido reproduzidos no arcabouço do planejamento urbano da legislação infraconstitucional que regulamenta os princípios constitucionais, 
notadamente em sua principal normativa, o Estatuto da Cidade (lei federal no ${ }^{-10.257}$, de 18 de novembro de 2001), o qual também disponibiliza uma expressiva variedade de instrumentos jurídicos e urbanísticos para tornar efetivos os princípios da reforma urbana.

Recentemente o Brasil também aprovou normas próprias para a gestão das grandes concentrações urbanas, o Estatuto da Metrópole (lei federal no 13.089, de 12 de janeiro de 2015), que "estabelece diretrizes gerais para o planejamento, a gestão e a execução das funções públicas de interesse comum em regiões metropolitanas e em aglomerações urbanas instituídas pelos Estados...”. Na Espanha não há legislação estrita análoga, e a normativa mais próxima provavelmente seja a Ley de Medidas para la Modernización del Gobierno Local (Ley 57/2003), cujos objetivos principais consistem em "atender à necessidade de uma liderança clara e diáfana diante da sociedade, o que exige executivos com grande capacidade de gestão para atuar rápida e eficazmente”. Tal legislação visa superar o "excessivo uniformismo", admitindo padrões de planejamento específicos e regras de desenvolvimento urbano particulares às grandes cidades e metrópoles.

Se na Espanha a efetividade dos Planes de Ordenación Urbana é baixa pelas razões mencionadas, no Brasil ocorre fenômeno parecido com os Planos Diretores (Santos Jr.; Montandon, 2011; Rolnik, 2009), cuja eficácia é comprometida tanto pela insuficiência dos dispositivos institucionais quanto pela ação política de atores desinteressados em sua vigência (sejam governamentais, sejam privados). A despeito das muitas diferenças sociais, institucionais e urbanísticas que os separam, há aspectos comuns aos dois países. Os principais deles são: atividade imobiliária altamente rentável; presença hegemônica de um ideário mercadológico da cidade; e difusão de concepções de gestão urbana que alastraram as teses da cidade como máquina de crescimento e do empresariamento urbano (Arantes; Vainer; Maricato, 2000; Maricato, 
2011). Nos dois países os planos urbanísticos têm se tornado instrumentos litúrgicos, com baixa incidência sobre o planejamento das cidades. Parcela de responsabilidade desse cenário pode ser atribuída às fortes pressões por administrações austeras do ponto de vista fiscal, a escassez e adversidades orçamentárias e às insuficiências do ordenamento institucional, mas é evidente que há determinações políticas, ideológicas e econômicas muito mais poderosas na conformação da política urbana, razão suficiente para que os estudos de marcos institucionais não se limitem ao exame de regras normativas. Normas importam sempre, mas o contexto sociopolítico diz muito sobre políticas urbanas e seus impactos.

Quadro 3

Comparativo do Marco Institucional da Política Urbana: Espanha/Brasil

\begin{tabular}{|c|c|c|}
\hline $\begin{array}{l}\text { REFERÊNCIA } \\
\text { INSTITUCIONAL }\end{array}$ & ESPANHA & BRASIL \\
\hline $\begin{array}{c}\text { Enunciados } \\
\text { Constitucionais }\end{array}$ & $\begin{array}{c}\text { Princípios da Política Social e } \\
\text { Econômica (artigo 47) }\end{array}$ & $\begin{array}{l}\text { Capítulo da Política Urbana } \\
\text { (artigo } 182 \text { e artigo 183) }\end{array}$ \\
\hline $\begin{array}{l}\text { Principal Legislação } \\
\text { infraconstitucional }\end{array}$ & $\begin{array}{c}\text { Ley de Suelo (LS) - } \\
\text { Ley 20/2014 } \\
\text { Real Decreto Legislativo 7/2015 }\end{array}$ & $\begin{array}{l}\text { Estatuto da Cidade (EC) } \\
\text { Lei no 10.257/2001 }\end{array}$ \\
\hline $\begin{array}{l}\text { Legislação específica } \\
\text { para grandes cidades }\end{array}$ & $\begin{array}{c}\text { Ley } 57 / 2003 \\
\text { (Ley de Modernización del } \\
\text { Gobierno Local) }\end{array}$ & $\begin{array}{l}\text { Lei Federal no 13.089/2015 } \\
\text { (Estatuto da Metrópole) }\end{array}$ \\
\hline $\begin{array}{l}\text { Concepção normativa } \\
\text { da propriedade }\end{array}$ & $\begin{array}{l}\text { Plusvalia é reconhecida e admitida } \\
\text { (CE e LS); função social tênue }\end{array}$ & $\begin{array}{c}\text { Subordinação à função social } \\
\text { (CF e EC) }\end{array}$ \\
\hline $\begin{array}{c}\text { Competência pela } \\
\text { efetivação da política } \\
\text { urbana }\end{array}$ & $\begin{array}{l}\text { Artigo } 148 \text { da CE: competência } \\
\text { "exclusiva" das comunidades } \\
\text { autônomas pela "ordenación del } \\
\text { territorio, urbanismo y vivienda", } \\
\text { mas há compartilhamento com } \\
\text { municípios (Ley } 7 / 1985 \text { - Ley } \\
\text { Reguladora de las Bases del } \\
\text { Régimen Local) }\end{array}$ & $\begin{array}{l}\text { Artigo } 182 \text { da CF: "política } \\
\text { de desenvolvimento urbano } \\
\text { executada pelo poder } \\
\text { público municipal"; sistema } \\
\text { federativo impõe gestão } \\
\text { compartilhada e cooperativa } \\
\text { em políticas públicas }\end{array}$ \\
\hline $\begin{array}{l}\text { Principal instrumento } \\
\text { de ordenamento } \\
\text { territorial e de } \\
\text { regulação do uso e } \\
\text { do solo }\end{array}$ & $\begin{array}{l}\text { Planes de Ordenación Urbana } \\
\text { (LS) }\end{array}$ & $\begin{array}{l}\text { Plano Diretor obrigatório } \\
\text { para municípios com } \\
\text { populaçãao superior a } 20 \text { mil } \\
\text { habitantes } \\
\text { (CF e EC) }\end{array}$ \\
\hline
\end{tabular}

Fonte: elaboração própria. 


\section{Jefferson 0. Goulart}

é professor do Departamento de Ciências Humanas da Universidade Estadual Paulista (Unesp), pesquisador do Cedec e líder do Grupo de Pesquisa Desenvolvimento Urbano Contemporâneo (GPDUC/CNPq).

\section{Bibliografia}

ALFONSIN, Betânia Moraes. 2008. A política urbana em disputa: desafios para a efetividade de novos instrumentos em uma perspectiva analítica de direito urbanistico comparado (Brasil, Colômbia e Espanha). Tese de Doutorado em Planejamento Urbano. Rio de Janeiro: UFRJ.

AYUNTAMIENTO DE VALENCIA. Oficina Municipal del Plan. Plan General de Ordenacion Urbana: normas urbanísticas. 17 jun. 2007. Disponível em: <https://www.valencia.es/planos_urbanismo/NORMATIVA/PGOU/ NormasUrbanisticas.pdf >. Acesso em: 19 maio 2016.

ARANTES, Otília; VAINER, Carlos; MARICATO, Ermínia. 2000. A cidade do pensamento único: desmanchando consensos. Petrópolis: Vozes.

ARAUJO JR., Miguel Etinger. 2013. Las competencias urbanísticas y la planificación metropolitana en el Estado autonómico español. Boletín Mexicano de Derecho Comparado, nueva serie, año XLVI, n. 138, pp. 879-907.

BLANCO, Ismael; SUBIRATS, Joan. 2012. Políticas urbanas en España: dinámicas de transformación y retos ante la crisis. Gepolítica(s), vol. 3, n. 1, pp. 15-33.

BOTELHO, Maurilio Lima. 2014. Teoria da crise em David Harvey: observações sobre Os Limites do Capital. Revista Continentes, ano 3, n. 4, pp. 66-111.

CASTELLS, Manuel. 1980. Cidade, democracia e socialismo. Rio de Janeiro: Paz e Terra.

CASTELLS, Manuel; BORJA, Jordi. 1996. As cidades como atores políticos. Novos Estudos Cebrap, n. 45, pp. 152-166.

CLARKE, Simon. 1991. Crise do fordismo ou crise da social-democracia? Lua Nova, n. 24, pp. 117-150.

COSTA, M. I. et al. 2013. Explorando nuevas políticas urbanas. Paper presentado al XI Congreso de la Associación Española de Ciencia Política y Administración, Sevilla, 18 a 20 setembro.

DE CÓRDOBA, Manuel B. F. 2007. Los planes de ordenación del territorio en España; de la instrumentación a la gestión. Paper presentado al V Congreso Internacional de Ordenación del Territorio, Málaga. 
DE LA ROSA, Francisco Javier Ullán. 2014. Sociología urbana: de Marx a Engels a las escuelas postmodernas. Madrid: Centro de Investigaciones Sociológicas.

GRIGGS, Steven; BLANCO, Ismael; SULLIVAN, Helen. 2010. Neoliberalism, crisis and local governance. Paper presentado al International Seminar Neoliberal Globalisation, Crisis and Local Governence, Barcelona. HARVEY, David. 2013. Os limites do Capital. São Paulo: Boitempo. 1996. Do gerenciamento ao empresariamento: a transformação da administração urbana no capitalismo tardio. Espaço Ẽ Debates, ano XVI, n. 39, pp. 48-65.

LOGAN, John; MOLOTCH, Harvey Luskin. 1987. Urban Fortunes: the political economy of place. Berkeley: University of California Press.

LÓPEZ, Isidro; RODRÍGUEZ, Emanuel. 2010. Fin de ciclo: financiarización, território y sociedade de propietarios en la onde larga del capitalismo hispano [1959-2010]. Madrid: Traficantes de sueños.

MARICATO, Erminia. 2011. O impasse da política urbana no Brasil. Petrópolis: Vozes.

MÁRQUEZ, Antonio Montel; NAREDO, José Manuel. 2011. El modelo inmobiliario español y su culminación en el caso valenciano. Barcelona: Icaria.

MEDRANO, José Antonio Ramos. 2015. Los 10 errores más básicos y frecuentes en el urbanismo español. Actualidad Jurídica Ambiental, n. 52, pp. 1-23.

MICHILES, Carlos et al. 1989. Cidadão constituinte: a saga das emendas populares. Rio de Janeiro: Paz e Terra.

PARELLADA, Ángela Matesanz. 2009. El suelo en la legislación urbanística española. Boletin $C F+S$ 51. (Des)regulaciones. Madrid: Departamento de Urbanismo y Ordenación del Territorio de la Escuela Técnica Superior de Arquitectura de Madrid.

PAMPILLIÓN, Rafael. Estructura de la economia espanola por sectores econômicos y empleo (2015). 25 fev. 2016. Disponível em: <http://economy.blogs. ie.edu/archives/2016/02/estructura-de-la-economia-espanola-porsectores-economicos-y-empleo.php>. Acesso em: 21 mar. 2018.

ROLNIK, Raquel. 2009. Democracia no fio da navalha: limites e possibilidades para a implementação de uma agenda de reforma urbana no brasil. Revista Brasileira de Estudos Urbanos e Regionais, v. 11, n. 2, pp. 31-50.

RULLAN, Onofre. 1999. La nueva Ley de Suelo de 1998 en el contexto del neoliberalismo postmoderno. Investigaciones Geográficas, Anales de La Universidad de Alicante - Instituto Universitario de Geografía, pp. 5-21. 
SALGADO, Carlos Fernández. 2011. Democracia y participación: el Plan General de Madrid de 1985. Cuadernos de Investigación Urbanistica - Ci[ur], año IV, n. 79, noviembre-deciembre. Madrid: Instituto Juan de Herrera.

SANTOS JR., Orlando Alves; MONTANDON, Daniel Todtmann. 2011. Os Planos Diretores Municipais pós-estatuto da cidade: balanço crítico e perspectivas. Rio de Janeiro: Letra Capital; Observatório das Cidades; IPPUR/UFRJ.

SECCHI, Bernardo. 2015. La ciudad de los ricos y la ciudad de los pobres. Madrid: Catarata.

SOUZA, Celina. 2007. Estado da arte da pesquisa em políticas públicas. In: HOCHMAN, G.; ARRETCHE, M.; MARQUES, E.C. (orgs.) Políticas Públicas no Brasil. Rio de Janeiro, Fiocruz.

VILLAÇA, Flávio. 2004. Uma contribuição para a história do planejamento urbano no Brasil. In: DEAK, Csaba; SCHIFFER, Sueli Ramos. (orgs.). O processo de urbanização do Brasil. São Paulo: Edusp. 


\section{D)}

\section{O MARCO INSTITUCIONAL DA POLÍTICA URBANA NA ESPANHA E APONTAMENTOS COMPARATIVOS COM O BRASIL}

JEFFERSON 0. GOULART

Resumo: O marco institucional da política urbana compreende normas que regulam o uso do solo, o ordenamento territorial e as competências dos diferentes níveis de governo. Na Espanha temos o governo central, as comunidades autônomas (comparáveis aos estados no Brasil) e os ayuntamientos (correspondentes às prefeituras). Esta análise ainda inclui a Ley de Suelo e os Planes de Ordenación Urbana, tomados como referência privilegiada para que o estudo não se limite aos aspectos normativos do arranjo institucional. Apesar das diferenças e aspectos particulares, a análise comparada do cenário espanhol com o arranjo institucional da política urbana no Brasil permite identificar impasses comuns, como a presença hegemônica de um ideário mercantil da cidade e concepções de gestão urbana que disseminam as teses do empresariamento urbano.

Palavras-chave: Política Urbana; Ley de Suelo; Planes de Ordenación Urbana; Espanha; Brasil.

\section{THE INSTITUTIONAL FRAMEWORK OF URBAN POLICY IN SPAIN AND COMPARATIVE NOTES WITH BRAZIL}

Abstract: The institutional framework of urban policy includes norms that regulate the actions of the State regarding land use, territorial planning and the competences of varying levels of government. In Spain, we have the central government, the comunidades autônomas (like the states in Brazil) and the ayuntamientos (local government). This analysis also includes the Ley de Suelo and Master Plans, taken as a privileged reference so that the study is not limited to the normative aspects of the institutional framework. Despite the differences and distinct aspects, this comparative analysis between 
Resumos | Abstracts

Spain and the Urban Policy in Brazil allows us to identify common impasses, such as the hegemonic presence of a mercantile ideology of the city and urban management concepts that have spread the theses of urban entrepreneurship.

Keywords: Urban Policy, Law of ground; Master Plans, Spain; Brazil.

Recebido: 09/08/2017 Aprovado: 13/03/2018 